\title{
METHOD OF EVALUATION OF THERMAL RESISTANCE OF MULTILAYER DEPOSITED METAL
}

\author{
A.A. BABINETS \\ E.O. Paton Electric Welding Institute, NASU \\ 11 Bozhenko Str., 03680, Kiev, Ukraine. E-mail: office@paton.kiev.ua
}

\begin{abstract}
At the present time there is no generally-accepted procedure of testing the thermal resistance of multilayer deposited specimens. The existing sufficiently widely used method of evaluation of thermal resistance, based on determination of number of heating-cooling cycles up to the appearance of a network of thermal cracks, does not allow carrying out a precise evaluation of thermal resistance during testing of multilayer deposited specimens possessing a rather high thermal resistance. The aim of the work consists in development or improvement of the procedure of evaluation of thermal resistance of the multilayer deposited metal, which could allow investigating the dynamics of propagation of thermal cracks in depth of the deposited layer and its change depending on characteristics of the deposited layers. The procedure, developed at the E.O. Paton Electric Welding Institute, was improved that made it possible to carry out the precise evaluation of thermal resistance of the deposited metal. It was found that the fusion line nature has a definite effect on thermal resistance of the specimen as a whole. In this case the surfacing of a ductile sublayer by wire Sv-08A contributes to arresting the growth of the thermal fatigue cracks and increase in total thermal resistance approximately by $20 \%$. The improved procedure can be used for the precise evaluation of thermal resistance of surfacing materials, used in manufacture or restoration surfacing of tools for hot deforming. 12 Ref., 1 Table, 7 Figures.
\end{abstract}

$\boldsymbol{K} \boldsymbol{e} \boldsymbol{y} \boldsymbol{w} \boldsymbol{o} \boldsymbol{r} \boldsymbol{d} \boldsymbol{s}:$ arc surfacing, multilayer deposited metal, procedure of tests

Thermal fatigue resistance (thermal resistance) is one of the main properties of tool steels, which are used in the process of manufacture or restoration of a wide assortment of tools for hot deforming of metals [1-3]. Among them there are different rolls of hot rolling mills, rollers of machines for continuous casting of billets, dies of hot stamping, etc.

As a result of cyclic thermal loads a network of relatively fine thermal cracks is appeared at the surface of these tools. These cracks cause the extraction of metal particles, accelerate wear and promote the rapid wear development [4, 5]. These damages, developing under complex service conditions, can lead not only to the rejection of products, but also to a premature damage of the tool, thus leading to the significant cost losses.

At present there is no generally-accepted procedure for testing the thermal resistance of the multilayer deposited specimens. The standard method of testing materials at thermal-mechanical loading [6] is impossible to apply to the materials, which are used for the restoration of parts of the metallurgical equipment, as the specimens, used in this method, have a cylindrical solid (up to $22 \mathrm{~mm}$ thickness) or hollow (2 mm wall thick- ness, up to $12 \mathrm{~mm}$ diameter) section. The specimens of this shape and sizes do not allow evaluating the effect on thermal resistance of the multilayer deposited metal of the specimen as a whole.

In this connection such tests are carried out more often by using different experimental procedures, in most of which the criterion of thermal resistance is a number of heating-cooling cycles up to the appearance of a network of thermal fatigue cracks [1, 2, 7-10]. The E.O. Paton Electric Welding Institute presents one of these procedures, as well as the designed laboratory equipment [10] which is characterized by the following advantages:

- sizes of the used specimens provide a required temperature gradient and stressed state, close to those occurring during service of real parts of the metallurgical equipment. In this case the specimens have a simple and convenient shape for manufacture without sharp transitions, playing role of stress raisers;

- method of heating and cooling is provided, which is mostly close to the real service conditions;

- possibility of adjustment and monitoring of heating and cooling temperature and reproducibility of these conditions for all the tested specimens is provided.

The process of testing by this procedure is as follows (Figure 1). As-deposited specimen 1 of 


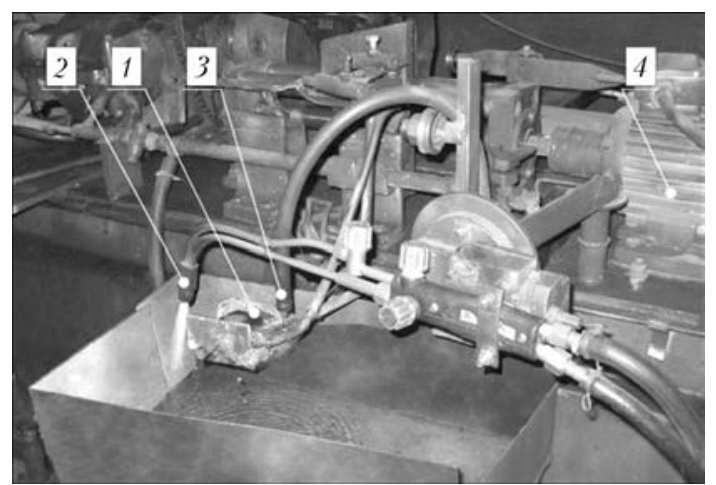

Figure 1. Equipment for testing the deposited metal thermal resistance (for designations see the text)

$40 \times 40 \times 40 \mathrm{~mm}$ size is installed into a mandrel of the equipment so that the grinded surface was faced to a heat source, i.e. gas-flame cutter 2 . During testing the mandrel with a specimen fixed in it is moved cyclically from the heat source to cooling source 3 (water supply hose) by means of drive 4 of mandrel reciprocal movement. Here, the uniform heating of the surface is provided in spot of $15-20 \mathrm{~mm}$ diameter. The heating duration is $11 \mathrm{~s}$, and cooling by a water jet is $8 \mathrm{~s}$.

At the mentioned duration of heating and cooling the temperature in the spot is growing during the first 8-10 test cycles, and then it is stabilized within $700-800{ }^{\circ} \mathrm{C}$ during heating and within $20-60{ }^{\circ} \mathrm{C}$ after cooling. Monitoring of temperature during tests is realized by using thermocouples. The thermal resistance is evaluated by the number of heating-cooling cycles up to the appearance and development of thermal crack net-

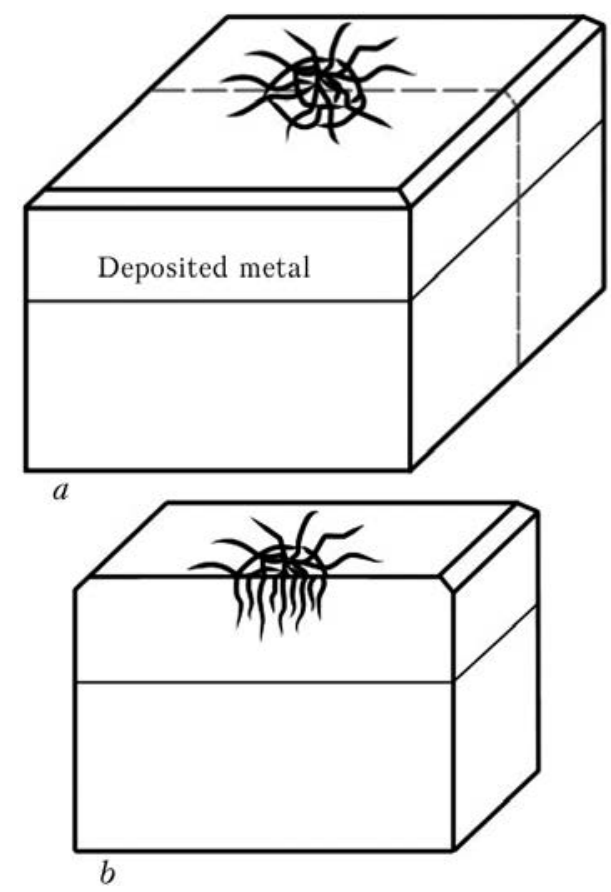

Figure 2. Scheme of specimen cutting for manufacture of macrosection: $a$ - specimen after testing; $b$ - after cutting work, visible by a naked eye, in the heat spot. To obtain the valid test results, 3-5 specimens of each type of the deposited metal are tested. After tests the specimens are cut in some cases in a transverse direction in the heat spot for evaluating the depth of crack propagation on the macrosections.

However, the investigations of thermal resistance of the deposited metal, made according to the mentioned procedure, showed $[4,11,12]$ that in the majority of cases the maximum number of heating-cooling cycles up to the appearance of the network of thermal cracks does not exceed 200 . Here, depth of crack propagation is $0.2-0.5$ $\mathrm{mm}$ and is not almost increased, at the further increase in cycle numbers only the crack opening is increased. Thus, during testing according to this procedure it is impossible to evaluate the dynamics and nature of development of the thermal fatigue cracks by thickness of the deposited layers.

The aim of the present work is the development and improvement of the procedure of evaluation of thermal resistance of the multilayer deposited metal, which would allow investigating the dynamics of thermal crack propagation in the depth of the deposited layer and its change depending on characteristics of the deposited layers.

To reach the put aim, the above-described test procedure was taken as a basis, which was improved in the following way. It was suggested to perform the test of specimens in several stages, each by duration of 200 heating-cooling cycles with the next grinding of surface after each stage. Grinding was made until the complete removal of thermal cracks, at the same time recording here their depth, that allowed evaluating the dynamics of crack propagation across the deposited metal thickness. These operations were repeated up to attaining the minimum possible thickness of the deposited working layer, $(1.5-2.0 \mathrm{~mm})$, after which the final stage of thermocycling without post grinding was performed. Further, the specimens were cut in heat spot (Figure 2) and then the depth and nature of thermal crack propagation were examined on the macrosections.

According to the mentioned procedure the thermal resistance of specimens of the multilayer deposited metal of four types was evaluated. For this, on billets of steel $40 \mathrm{Kh}$ electric arc surfacing of the working layer was performed by flux-cored wire PP-Np-25Kh5FMS using the following variants: surfacing without a sublayer, and surfacing of the working layer with a sublayer deposited 


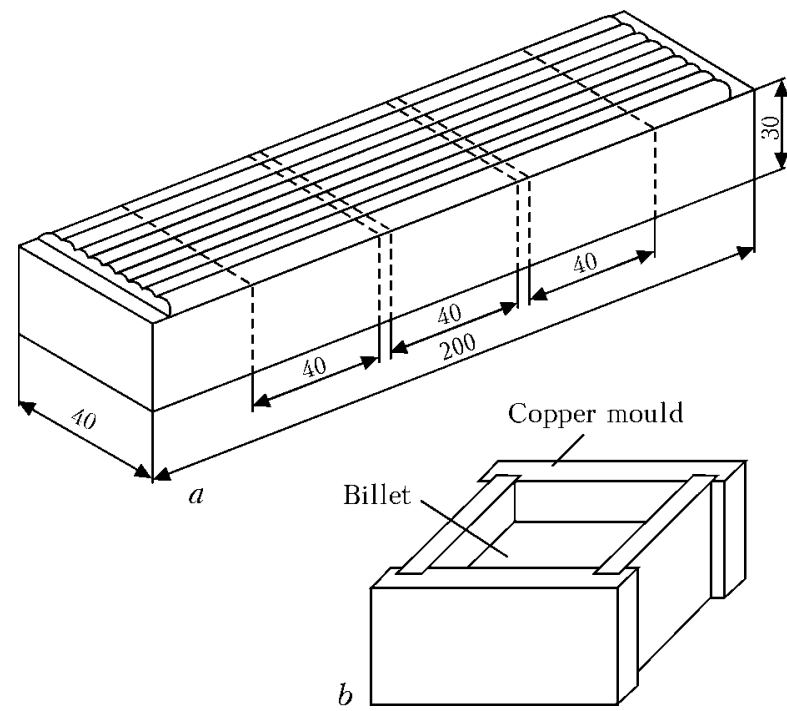

Figure 3. Scheme of manufacture of multilayer deposited specimens for investigation of thermal resistance in automatic submerged arc surfacing $(a)$ and semiautomatic surfacing with self-shielding flux-cored wires $(b)$

by wire $\mathrm{Sv}-08 \mathrm{~A}$. Taking into account that the thermal fatigue is greatly affected by stress raisers, sharp transitions of the shape, structural heterogeneity, etc. [1, 2], it was supposed that the depth and shape of penetration also have effect on the metal thermal resistance. Coming from this, surfacing of experimental specimens was performed using two technologies:

- automatic multibead multilayer surfacing was performed on plates of $30 \times 40 \times 200 \mathrm{~mm}$ sizes, whereupon the test specimens of $40 \times 40 \times$ $\times 40 \mathrm{~mm}$ size were cut from the surfaced billets (Figure 3, a);

- billet of $30 \times 40 \times 40 \mathrm{~mm}$ size was placed into a dismountable copper mould and semi-automatic electric arc multilayer surfacing with selfshielding flux-cored wires was performed $\left(\mathrm{Fi}^{-}\right.$ gure $3, b)$.

Automatic surfacing on the plates by solid wire Sv-08A was made under flux AN-348A, and surfacing by wire PP-Np-25Kh5FMS was made under flux AN-26P. Diameter of all the wires was $2.0 \mathrm{~mm}$. Surfacing conditions were as follows: $I_{\mathrm{s}}=300-350 \mathrm{~A}, U_{\mathrm{s}}=28-30 \mathrm{~V}, v_{\mathrm{s}}=$ $=20 \mathrm{~m} / \mathrm{h}$. Surfacing pitch was equal to $40 \%$ of the deposited bead width.

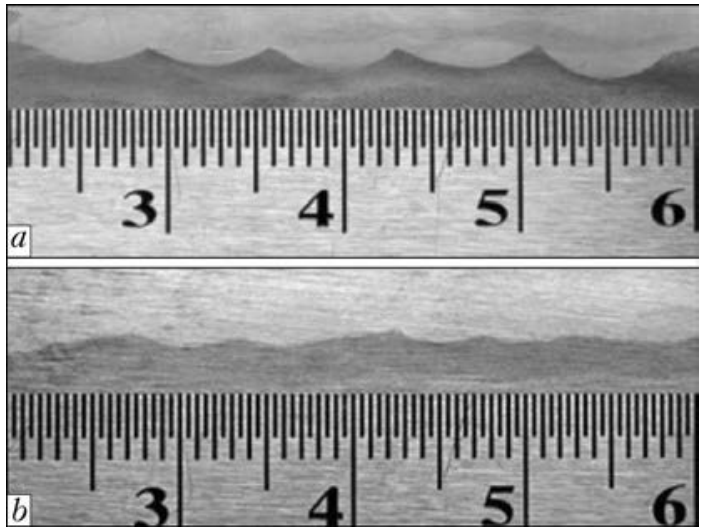

Figure 4. Transverse macrosections deposited by automatic (a) and semiautomatic (b) method

Semiautomatic surfacing in the cooper mould by solid wire $\mathrm{Sv}-08 \mathrm{~A}$ was performed in $\mathrm{CO}_{2}$ shielding gas, wire diameter was $0.8 \mathrm{~mm}$. diameter of PP-Np-25Kh5FMS self-shielding fluxcored wire was $1.8 \mathrm{~mm}, I_{\mathrm{s}}=200-220 \mathrm{~A}, U_{\mathrm{s}}=$ $=22-24 \mathrm{~V}$.

On all the specimens the total thickness of the sublayer was $3-4 \mathrm{~mm}$, and that of the working layer was 5-6 mm. Hardness and also data of spectral analysis by chemical composition of the deposited metal are given in the Table. Symbols $\mathrm{A}$ and $\mathrm{S}$ in the Table denote automatic and semiautomatic surfacing, respectively.

After deposition, one specimen from each batch was cut perpendicular to surfacing direction for the metallographic examinations. It is seen on the manufactured macrosections of the deposited metal that application of smaller diameter wire in combination with oscillating movements of the electrode in semiautomatic surfacing provided a smaller depth of penetration and more smooth fusion line, as compared with submerged arc surfacing (Figure 4).

Then for comparison, the thermal resistance tests were performed according to the standard procedure up to the appearance of developed network of thermal cracks. The test results showed (Figure 5) that all four types of the deposited metal have almost similar, sufficiently high thermal resistance. At the same time, two regularities were noted:

Chemical composition and hardness of deposited metal depending on method of surfacing

\begin{tabular}{|c|c|c|c|c|c|c|c|c|c|}
\hline \multirow{2}{*}{$\begin{array}{l}\text { Specimen } \\
\text { number }\end{array}$} & \multirow{2}{*}{ Type of deposited metal } & \multirow{2}{*}{$\begin{array}{l}\text { Method } \\
\text { of } \\
\text { surfacing }\end{array}$} & \multicolumn{6}{|c|}{ Composition of alloying elements, wt.\% } & \multirow{2}{*}{$\begin{array}{c}\text { Hardness } \\
H R C\end{array}$} \\
\hline & & & $\mathrm{C}$ & $\mathrm{Si}$ & $\mathrm{Mn}$ & $\mathrm{Cr}$ & $\mathrm{V}$ & Mo & \\
\hline 1.1 & \multirow[t]{2}{*}{ PP-Np-25Kh5FMS (without sublayer) } & A & 0.24 & 0.72 & 0.53 & 4.90 & 0.35 & 0.95 & $48-50$ \\
\hline 1.2 & & $\mathrm{~S}$ & 0.26 & 0.79 & 0.64 & 5.50 & 0.40 & 1.01 & $49-51$ \\
\hline 2.1 & \multirow[t]{2}{*}{ Sv-08A sublayer + PP-Np-25Kh5FMS } & A & 0.24 & 0.74 & 0.56 & 5.10 & 0.37 & 0.97 & $48-50$ \\
\hline 2.2 & & $\mathrm{~S}$ & 0.26 & 0.76 & 0.64 & 5.40 & 0.40 & 0.99 & $49-51$ \\
\hline
\end{tabular}




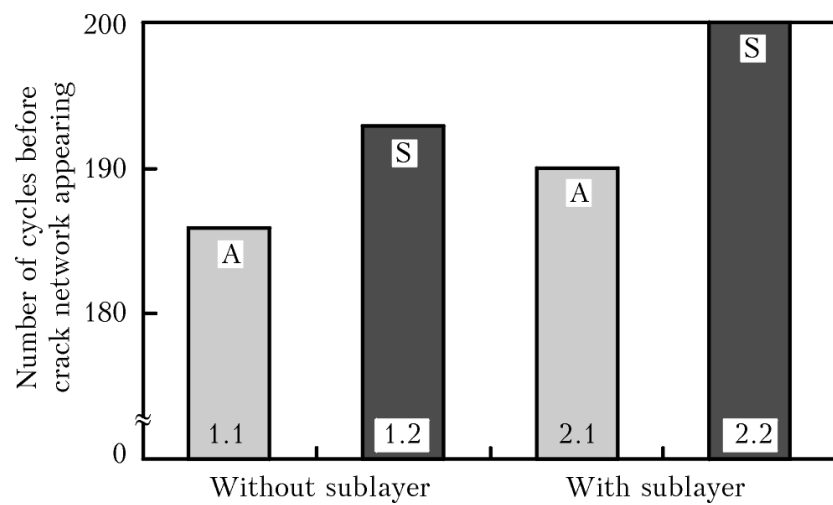

Figure 5. Thermal resistance of specimens 1.1-2.2 deposited by automatic submerged arc (A) and semiautomatic surfacing with self-shielding wire $(\mathrm{S})$

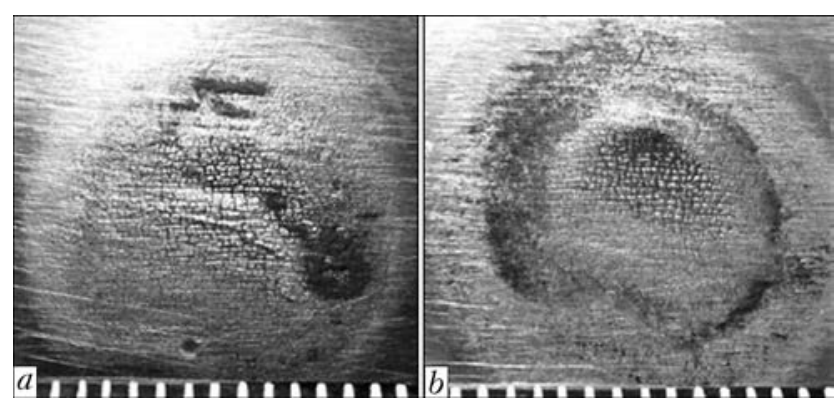

Figure 6. Appearance of surface of specimens, deposited by flux-cored wire PP-Np-25Kh5FMS without sublayer $(a)$ and with sublayer deposited by wire Sv-08A $(b)$, after thermal resistance testing

- thermal resistance of specimens, deposited by semiautomatic method is higher than that in automatic surfacing;

- surfacing of the sublayer contributes to increase in thermal resistance.

The first regularity is, probably, explained by the fact that in specimens, deposited by semiautomatic method, the decrease in depth of penetration and more uniform fusion boundary between separate deposited beads/layers contributes to decrease in levels of chemical and structural heterogeneity, that influences positively on the thermal resistance. To explain the second regularity, the specimens were subjected to tests using the above-mentioned improved procedure.

Analysis of obtained results showed that the specimens, deposited without sublayer, have a greatly developed network of thermal cracks (Figure $6, a$ ). Thickness of the grinded layer after each 200 test cycles was approximately $0.35-0.40 \mathrm{~mm}$. The minimum thickness of the deposited wear-resistant layer was attained after 2000 test cycles, then the specimens were cut in heat spot, and macrosections were manufactured from them (Figure 7, a). As is seen, in this case the thermal cracks are transferred from the deposited metal into the base one.

In specimens with the sublayer, deposited by wire Sv-08A, the less expressed network of ther-
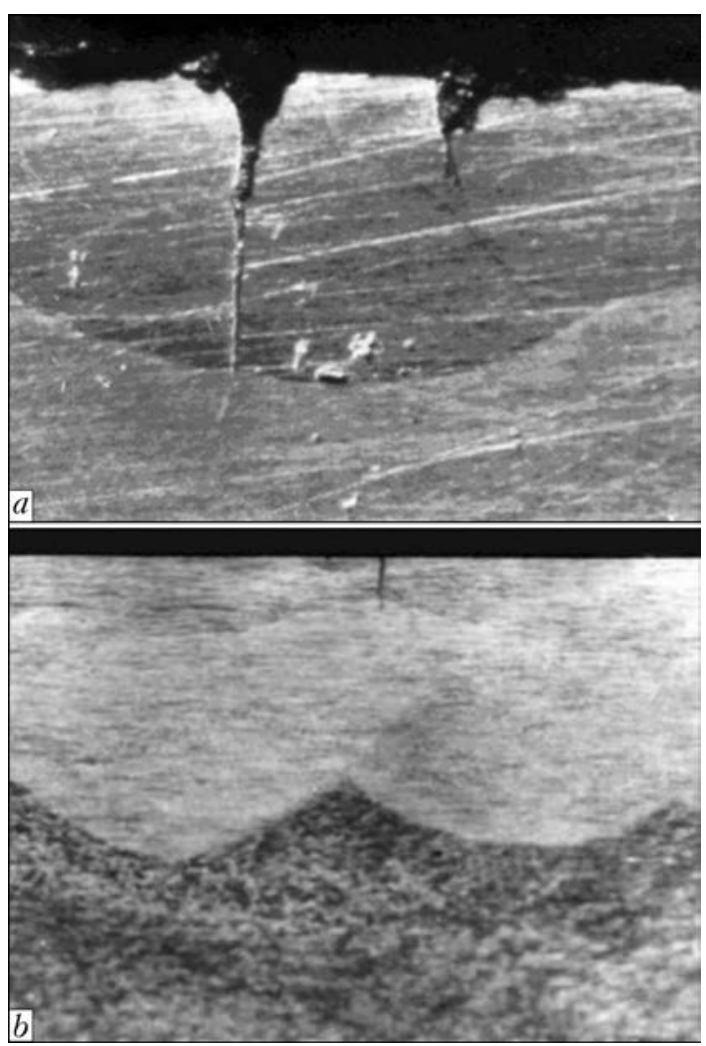

Figure 7. Macrosection of specimens, deposited without sublayer $(a)$ and with Sv-08A sublayer $(b)$, after thermal resistance testing

mal cracks is observed (Figure $6, b$ ). In this case the depth of cracks propagation across the thickness was also smaller. The thickness of the grinded layer after each 200 test cycles was approximately $0.20-0.25 \mathrm{~mm}$. Taking into account a negligible removal of the material, it was possible to carry out 2400 test cycles on these specimens. As-tested specimens were also cut and macrosections were prepared (Figure $7, b$ ). In this case the cracks are passed through the wearresistant layer and arrested in low-carbon sublayer.

Thus, the improvement of procedure of thermal resistance testing by carrying out several stages with regrinding of the specimen surface allowed evaluating the dynamics and nature of development of thermal fatigue cracks across the thickness of deposited layers and revealing the effect of the sublayer on the nature of their propagation.

\section{Conclusions}

1. Existing and sufficiently widely used method of evaluation of thermal resistance, based on determination of number of heating-cooling cycles up to appearance of a network of thermal cracks, does not allow making a precise evaluation of crack resistance at testing of multilayer deposited 
specimens, possessing a rather high thermal resistance.

2. Improvement of procedure of thermal resistance tests by carrying out several stages with a regrinding of the specimen surface made it possible to evaluate the development of thermal fatigue cracks across the thickness of deposited layers and to reveal the effect of sublayer on nature of propagation of the thermal fatigue cracks.

3. It was established that depth of penetration and nature of fusion line of deposited layers has a definite effect on thermal resistance of the deposited specimen as a whole, that it is necessary to take into account in selection of technology and technique of surfacing.

1. Dulnev, R.A., Kotov, P.I. (1980) Thermal fatigue of metals. Moscow: Mashinostroenie.

2. Tylkin, M.A. (1971) Increase in service life of metallurgical equipment parts. Moscow: Metallurgiya.

3. Frumin, I.I. (1961) Automatic electric arc surfacing. Kharkov: Metallurgizdat.

4. Ryabtsev, I.A., Kondratiev, I.A. (1999) Mechanized electric arc surfacing of metallurgical equipment parts: Refer. Book. Kiev: Ekotekhnologiya.
5. Tolstov, I.A., Pryakhin, A.V., Nikolaev, V.A. (1990) Increase in serviceability of hot working tool. Moscow: Metallurgiya.

6. GOST 25.505-85: Methods of mechanical testing of metals. Method of test on low-cycle fatigue in thermomechanical loading.

7. Shkolnik, L.M. (1978) Procedure of fatigue tests: Refer. Book. Moscow: Metallurgiya.

8. Marek, A., Junak, G., Okrajni, J. (2009) Fatigue life of creep resisting steels under conditions of cyclic mechanical and thermal interactions. Archives of Materials Sci. and Eng., Vol. 40, Issue 1, 37-40.

9. Lanin, A.G. (1998) Methods of determination of thermal resistance (Review). Zavod. Laboratoriya. Diagnostika Materialov, 3, 31-47.

10. Ryabtsev, I.I., Chernyak, Ya.P., Osin, V.V. (2004) Block-module unit for tests of deposited metal. Svarshchik, 1, 18-20.

11. Ryabtsev, I.A., Babinets, A.A., Ryabtsev, I.I. (2011) Effect of ductile sub-layer on heat resistance of multilayer deposited metal. The Paton Welding J., 10, 18-21.

12. Babinets, A.A., Ryabtsev, I.A., Kondratiev, I.A. et al. (2014) Investigation of thermal resistance of deposited metal designed for restoration of mill rolls. Ibid., 5, 16-20.

Received 09.07.2015 